\title{
Concepções de ciência e educação: contribuições da história da ciência para a formação de professores
}

\author{
Gabriela Marko ${ }^{1}$ \\ ORCID: https://orcid.org/0000-0001-5491-9029 \\ Ermelinda Moutinho Pataca ${ }^{1}$ \\ ORCID:https://orcid.org/0000-0002-0808-4865
}

\section{Resumo}

No campo do ensino de ciências, nas últimas décadas, reflexões teóricas e atividades práticas vêm sendo desenvolvidas a fim de incorporar a abordagem da História, Filosofia e Sociologia das Ciências em currículos, metodologias de ensino, materiais didáticos e programas de formação de professores. Essas discussões, mais presentes nas licenciaturas, pouco aparecem na graduação de pedagogo(a)s, responsáveis pela educação no Ensino Fundamental I. Este trabalho pretende contribuir para preencher essa lacuna. Trata-se de uma pesquisa participante realizada na disciplina optativa de História da Ciência, oferecida em 2017 na Faculdade de Educação da Universidade de São Paulo para alunos da pedagogia, aberta também para estudantes de outros cursos de licenciatura. Esta investigação tem como objetivo destacar a construção de concepções mais complexas e dinâmicas de ciência e educação que se desenvolveu durante a disciplina, a partir da escolha da leitura de determinados autores. Verificou-se o reconhecimento, por parte dos próprios educadores em formação, de contribuições dos debates e recursos didáticos desenvolvidos por eles para uma compreensão mais ampla e aprofundada da ciência e sua historicidade, das relações com a sociedade e da significação de ciência como cultura. Nesse processo, elaboraram associações com o ensino e fundamentos da educação, tanto no cenário teórico como em atividades práticas. Isso favoreceu suas formações enquanto sujeitos críticos e refletiu diretamente sobre suas práticas docentes.

\section{Palavras-chave}

História da ciência - Formação de educadores - Pedagogia.

1- Universidade de São Paulo, São Paulo, SP, Brasil.

Contatos: gabrielamark08@gmail.com; ermelinda.pataca@gmail.com. 


\section{Concepts of science and education: contributions from the history of science to the formation of teachers}

\section{Abstract}

In the field of science teaching, over the last decades, theoretical reflections and practical activities have been developed in order to incorporate the approach of History, Philosophy, and Sociology of Sciences in curricula, teaching methodologies, learning materials, and teacher training programs. These discussions, which are more usually found in undergraduate degrees, hardly appear in the formation of pedagogues, who are responsible for the education in Elementary School. This paper intends to contribute to fill this gap. It is a participant research realized in the optional course of History of Science, offered in 2017 by the School of Education at the University of São Paulo for pedagogy students, also open to other undergraduates. This research aims to highlight the construction of more complex and dynamic conceptions of science and education that developed throughout the classes, resulting from the choice of reading certain authors. Educators themselves acknowledged the contributions arising from the debates and didactic resources with the purpose of a broader and deeper understanding of science and its historical nature, of the relations with the society and the meaning of science as culture. In this process, they devised associations with teaching and fundamentals of education, both in the theoretical framework and in practical activities. Their training therefore benefitted students with critical judgment which directly impacted their teaching practices.

\section{Keywords}

History of science - Teacher training - Education.

\section{Introdução}

Este artigo contempla um recorte da pesquisa de mestrado intitulada Contribuições da história da ciência para a formação de pedagogo(a) $s^{2}$, cujo mote é ampliar relações verificadas entre História, Filosofia e Sociologia da Ciência (HFSC) e o ensino de ciências (EC) para o campo da educação, focando na formação de professores dos anos iniciais do Ensino Fundamental (EF). Este artigo tem o objetivo de apontar que a História da Ciência (HC) na formação de professores, e em especial de pedagogos, propicia a elaboração de concepções de ciência e educação mais complexas e dinâmicas. Estas, por sua vez, favorecem a formação da identidade docente do professor e sua criticidade, tangenciando noções sobre a construção de conhecimentos e a ressignificação de dimensões do educar.

2- Desenvolvida na Faculdade de Educação da Universidade de São Paulo (FEUSP) e financiada pela Coordenação de Aperfeiçoamento de Pessoal de Nivel Superior (CAPES). 
Há, também, implicação direta nas reflexões sobre suas práticas docentes, além de contemplar recursos que instrumentalizam suas atividades em sala de aula.

Partiremos de argumentos a favor da presença da abordagem das HFSC, especialmente da HC, no EC e na formação de educadores. Trabalhos acadêmicos têm se debruçado sobre esses temas ${ }^{3}$, como o dossiê História das ciências e ensino de ciências publicado pela Revista Brasileira de História da Ciência (2014), cujas produções apresentam propostas de um ensino que contemple esse enfoque. Os textos decorrem de debates sobre quais concepções de ciência vêm se desenvolvendo nas escolas. E é justamente sobre a construção dessas concepções de ciência na formação de educadores que trataremos aqui.

Matthews (1995) defende que apresentar os conteúdos de forma contextualizada possibilita um processo de ensino-aprendizagem mais coerente, abrangente e, portanto, significativo aos estudantes. Favorece a concepção de que a ciência é mutável, instável, contém hipóteses transitórias e revela transformações no pensamento científico, de acordo com os contextos históricos, sociais, culturais e políticos nos quais estão inseridos os cientistas, tendo em vista o objetivo de seus trabalhos. Essa abordagem opõe-se à noção de ciência como reveladora de uma única verdade e, assim, a ideia de correto é reelaborada, sendo necessário levar em conta os contextos nos quais estão inseridos os cientistas, os argumentos e os interesses políticos e econômicos que compõem cada discussão. 0 autor também defende que os alunos se apropriem da natureza da ciência, ou seja, que reconheçam práticas e recursos necessários na produção e sustentação dos conhecimentos científicos. Diversos autores (HODSON, 1992; NEWERLA, 2000; DUARTE, 2004; FIGUEIRÔA, 2009; FORATO, 2009; ALVIM; ZANOTELLO, 2014; SILVA, 2014; GANDOLFI, 2015; SCMIEDECKE, 2016) também legitimam tal perspectiva, sendo essa muito difundida em pesquisas acerca da HFSC e EC.

Para Santos (2005), a educação deve favorecer a formação da cidadania, sendo esse um conceito complexo já que é modificado conforme a dinâmica da sociedade, dependendo dos interesses em debate. A luta pela cidadania, na contemporaneidade, exige direito ao conhecimento; afınal, a sociedade em rede, causada pela revolução das tecnologias, traz uma nova lógica que descentraliza o acesso à informação e facilita a livre comunicação entre as pessoas. 0 conhecimento é pressuposto para a emancipação, e os cidadãos, dotados de conhecimentos, serão capazes de afetar decisões políticas e a sociedade na qual estão inseridos. Assim, o desenvolvimento de uma cidadania cultural, crítica e ativa depende também de se ter conhecimento sobre ciência. Ao contemplar debates éticos e culturais, colocando diversos saberes em pauta, se afeta a concepção de mundo e de cidadania.

Referindo-se especialmente à importância da HFSC na formação de professores, Gandolfı e Figueirôa (2017) realçam a necessidade da construção de concepções mais críticas da ciência, a partir de questionamentos sobre uma visão de ciência neutra e dogmática. Para que o professor se forme por uma perspectiva emancipatória e política, é importante que entre em contato com a natureza da ciência bem como suas relações com outros campos do conhecimento. Por essa abordagem, o professor, além de lidar

3- Não pretendemos fazer uma revisão exaustiva desses trabalhos; foram escolhidos alguns cuja abordagem é mais próxima da argumentação deste artigo. 
melhor com o conteúdo e com os conceitos a serem trabalhados nas escolas, estará mais preparado para escolher e elaborar materiais, metodologias e avaliações em suas próprias práticas docentes. Dessa maneira, afirmam as autoras,

[...] o professor de Ciências poderia adquirir autonomia para questionar e ressignificar o quê e como ensina o conhecimento científico, deixando de apenas consumir livros didáticos ou, quando muito, alguma pesquisa acadêmica, mas sim se tornando um crítico desse conhecimento técnico que incorpora em sua prática. (GANDOLFI; FIGUEIRÔA, 2017, p. 12).

As autoras analisam um estudo de caso da prática docente a partir do uso de textos e fontes histórico-científicos, a fim de verificar seu impacto e contribuições nesse processo formativo no que tange à natureza da ciência. Concluem que essa estratégia contribui com a formação e atuação crítica dos professores e recomendam possibilidades de formação continuada para que professores de ciências também utilizem esse recurso.

A pesquisa desenvolvida por Chinelli, Ferreira e Aguiar (2010), investiga quais seriam as concepções epistemológicas contempladas pelos professores de ciências e notou que ocorrem distintas compreensões concomitantes em uma mesma instituição, ou mesmo no conjunto de percepções de um mesmo profissional, ocasionando possíveis dificuldades no EC. Reiteram a necessidade de que cursos de formação de professores incluam a abordagem da HC e ressaltam a importância de se debaterem aspectos dos estudos sociológicos sobre educação, principalmente no que se refere ao currículo. Essa possibilidade favorece a autonomia do docente na definição dos objetivos do ensino, na seleção dos conteúdos e das situações de aprendizagem. As renovações didáticas não devem ficar apenas em âmbito teórico, mas precisam contemplar experiências de reflexão sobre as práticas, como

[...] exemplos concretos das profundas relações existentes entre a ciência, a tecnologia, a sociedade e o ambiente; e oportunidades para que se discutam a democratização do conhecimento e questões éticas relacionadas à produção e à distribuição de produtos científicos e tecnológicos. (CHINELLI, FERREIRA; AGUIAR, 2010, p. 33).

Desse modo, para que se utilizem do enfoque das HFSC em sua prática docente, é fundamental que educadores entrem em contato com essas perspectivas e se apropriem criticamente delas. Por mais que a educação científica ocorra de modo vertical, em todos os anos escolares a formação dos professores incumbidos de lecionar em cada etapa é diferente. Enquanto responsáveis pelo EC no EF II e Ensino Médio se especializam em sua área, pedagogos, atores no EF I, cumprem um currículo significativamente diferente na formação inicial.

Mesmo com uma produção cada vez maior que aproxima a HFSC do EC, pouco chega à pedagogia. Por um levantamento feito em 2017, através dos sites das universidades federais e estaduais de São Paulo - Universidade Federal do ABC (UFABC), Universidade Federal de São Carlos (UFSCar), Universidade Federal do Estado de São Paulo (Unifesp), Universidade Estadual Paulista (Unesp), Universidade de São Paulo (USP), Universidade 
Estadual de Campinas (Unicamp) - verificou-se um número reduzido de disciplinas de HFSC destinada à pedagogia. Oferecidas como optativas ou eletivas, não ocorrem com frequência regular. A pouca presença dessa abordagem na graduação revela-se como uma contradição ao notar que, recém-formado, o professor polivalente depara-se com documentos de orientação curricular como os Parâmetros Curriculares Nacionais (1998), que contemplam a perspectiva das HFSC na área de ciências naturais, já a partir do EF I: "A História da Ciência tem sido útil nessa proposta de ensino, pois o conhecimento das teorias do passado pode ajudar a compreender as concepções dos estudantes do presente, além de também constituir conteúdo relevante do aprendizado" (BRASIL, 1998, p. 21).

Assim, chega-se ao ponto central deste artigo. Trata-se da apresentação de dados coletados e análises feitas a partir da pesquisa participante realizada durante a disciplina de História da Ciência, ministrada por Ermelinda Pataca e oferecida como optativa aos alunos de graduação em pedagogia e também provenientes de outros cursos, na FEUSP. Nosso objetivo é caracterizar o processo de construção de concepções de ciência e educação pelos discentes, admitindo as ideias e argumentos principais revelados em suas falas e nos recursos didáticos utilizados por eles, ressaltando também relações que estabeleceram com a educação, a partir da mediação da professora e suas escolhas bibliográficas. Pretendemos realçar as contribuições da HC para a formação de educadores, admitindo implicações diretas na educação básica, por propiciar uma compreensão mais profunda e crítica sobre as dinâmicas de produção do conhecimento, afetando também a prática docente.

\section{Caracterização e metodologia da pesquisa participante}

As aulas aconteceram entre março e julho de 2017 e a programação contemplou diversas atividades, como discussões teóricas e dinâmicas práticas, organizadas em quinze encontros presenciais, que ocorreram às sextas-feiras à noite, com média de vinte alunos em cada. A maioria era estudante de pedagogia, mas alguns eram licenciandos em física ou astronomia. Além disso, uma parcela já havia vivenciado outros cursos de graduação, como física, química, arte ou história, e realizado pesquisas de iniciação científica em EC.

Os encontros presenciais eram divididos em dois momentos distintos. 0 primeiro, voltado para leitura e discussão de um ou dois textos, era conduzido pelos alunos ou pela professora em seminários. 0 segundo consistia em uma atividade complementar coordenada pela docente, como aulas expositivas e orientação para atividades seguintes. Essas aulas teóricas foram intercaladas por três atividades práticas: dois estudos do meio e uma mostra de recursos didáticos preparados pelos alunos.

Ao longo da disciplina, foram privilegiados textos clássicos da história e sociologia das ciências, cobrindo um quadro conceitual desenvolvido desde a década de 1930, com a emergência da sociologia das ciências aos dias atuais. Algumas das publicações são mais específicas, apresentando metodologias e abordagens diversas, como as influências dos valores culturais na construção das ciências, o ethos científico (MERTON, [1936] 2013), a construção social da verdade (SHAPIN, [1995] 2013), as rupturas na construção histórica das ciências (KUHN, [1962] 2013), as negociações científicas e controvérsias (LIMA; HOCHMAN, 1996; DOMINGUES; SÁ, 2003) e as imbricações entre política e 
ciência (LIMA; HOCHMAN, 1996; ABRANTES, 1998). Deste modo, pretendia-se fomentar discussões sobre campos disciplinares específicos, construções conceituais, práticas, técnicas e representações científicas. A escolha dos textos, de maneira geral, privilegiou relações entre a HC e a história da educação científica, já que se tratava de um curso voltado à formação de professores.

A disciplina foi estruturada em dois grandes blocos. Esta escolha reforça a necessidade de que se compreendam as atividades científicas circunstancialmente, em períodos de longa duração, envolvendo constituição de saberes e práticas que rompem com as barreiras disciplinares constituídas atualmente.

Entre as aulas 2 e 6, os textos (MERTON, [1936] 2013; SOLLA PRICE, 1976; ROSSI, 1989; KUHN, [1962] 2013) versaram sobre Revolução(ões) Científica(s), com temas voltados principalmente para astronomia, física, aproximações entre teoria e prática, experimentação, construção de instrumentos e o desenvolvimento da técnica. Ocorreu a visita à exposição Brincar ou ensinar?, realizada pelo Museu da Educação e do Brinquedo (MEB), cujo objetivo inicial seria a apresentação do Poliopticon, brinquedo composto por lentes e tubos para montagem de instrumentos científicos, temática abordada nesses textos.

Já no segundo bloco (aulas 7 a 13), foram trabalhadas questões relativas às Ciências da Vida e da Terra, emergentes na segunda metade do século XVIII e institucionalizadas nos séculos seguintes. Os textos debatidos analisam a constituição da História Natural (ABRANTES, 1998; LOPES, 2005; PATACA, 2016), das ciências da vida e das ciências históricas na natureza (geologia, biologia evolutiva, paleontologia, arqueologia), tomando a evolução como um conceito estruturante às ciências da Vida e da Terra (MAYR, 2005; DOMINGUES; SÁ, 2003; LIMA; HOCHMAN, 1996). Nesta parte do curso, a HC no Brasil foi abordada com maior ênfase, revelando um contexto histórico com ênfase local ou regional.

Essa parte teórica foi complementada com o estudo do meio realizado nos espaços da Pinacoteca do Estado - focando nas obras dos séculos XVII a XIX que retratam olhares e atividades do Império Português na América, por pinturas de paisagens feitas por viajantes no século XIX - e no atual Jardim da Luz, que foi o primeiro jardim botânico da cidade de São Paulo e sofreu intensas remodelações no mesmo século, associando-se às concepções estéticas e científicas do período, contrapondo as pinturas observadas na Pinacoteca.

Todo esse processo de construção conceitual e prática foi retomado a partir de uma dinâmica na penúltima aula, denominada AulaSíntese. A atividade foi conduzida pela pesquisadora com dupla intenção: explicitar os conteúdos abordados ao longo da disciplina e compartilhar as análises parciais da pesquisa com os estudantes.

Para o último encontro, os grupos construíram recursos didáticos como instrumentos, experimentos ou atividades pedagógicas, compondo uma mostra interna. 0 desafio seria buscar relações entre as concepções de ciências em construção e o EC. Esse momento foi fundamental, pois aproximou ainda mais os debates com a atuação dos professores em formação, em sua prática docente. Além de construir materiais e atividades didáticas, puderam formar-se pelas próprias experiências que vivenciaram ali.

Como concepção, sistemática de coleta de dados e interpretação, optamos pela metodologia da pesquisa participante que está fundamentada em dois atores centrais: a pesquisa e a participação, de maneira equilibrada. Pesquisar não é apenas o uso de técnicas de aquisição e organização de dados, mas as análises produzem-se "por uma 
construção categorial que depende das questões iniciais, da teoria que se maneja, e da posição histórica a partir da qual o teórico - consciente ou inconscientemente - enxerga a sociedade" (EZPELETA; ROCKWELL, 1986, p. 86).

Segundo as autoras, participar é mais do que estar presente e colaborar, é também ser sujeito da construção de conhecimento. Destacam a importância de contextualizar os sujeitos da pesquisa: indivíduos que interagem, ensinam, aprendem e se modificam no percurso estão envolvidos em processos sociais, que instigam o pesquisador e são antecedentes às suas próprias ações na investigação. Nesse contexto, a observação participante é meio de interação entre o pesquisador e os sujeitos, possibilitando uma relação mais pessoal. Ghedin e Franco (2008) compreendem que, pela observação participante, a imagem do pesquisador se configura no desenrolar da atividade, sendo marcada pelos parâmetros do próprio grupo. De modo semelhante, a percepção sobre o grupo ocorre processualmente e circunscrita pelas relações que ocorrem durante a interação.

As coletas de dados e análises aqui propostas envolvem a participação dos alunos, da pesquisadora e da professora. A atuação da professora contemplou o planejamento das atividades, escolha dos textos a serem abordados e mediação durante as aulas. Seu exercício favoreceu relações entre as ideias de autores e o contexto histórico no qual estavam inseridas, elucidando causas, consequências e interesses por trás da construção e circulação de determinados conhecimentos. Também foi responsável pela explicação de conceitos científicos e forneceu diversas referências como livros ou filmes que dialogam com os debates ocorridos durante os seminários.

A participação da pesquisadora foi motivada pelo fato de ela mesma ter cursado a disciplina em questão, em 2010, durante sua formação inicial em pedagogia - o que despertou interesse a ponto de investigar essa temática no mestrado. Seu contato com os alunos ocorreu durante atividades programadas, conversas paralelas antes ou ao final das aulas e estudos do meio. Responsabilizou-se pela coleta de dados, por meio da observação e comunicação nos encontros, sendo que o ocorrido em sala de aula foi gravado em áudios e as considerações sobre o desenvolvimento das atividades foram apontadas em um caderno de registros. Essas anotações abrangem falas dos alunos e da professora, organizadas de maneira sintética, contemplando os conceitos apresentados, bem como os recursos didáticos utilizados para a comunicação deles.

Outro aspecto marcante foi o diálogo entre pesquisadora e estudantes na Aulasintese. Compartilhamos os resultados parciais com os alunos, convidando-os a opinarem sobre os direcionamentos do trabalho. Esse foi um elemento que favoreceu a configuração dos alunos na pesquisa - suas presenças e contribuições - não somente como objetos de análise, mas também enquanto sujeitos participativos. Essas sínteses foram de extrema importância tanto em termos didáticos, para a retomada de conceitos principais sobre ciência e educação, abordados em aula, quanto para nossa própria revisão sobre ponderações e conceitos estruturantes da disciplina.

As análises também estão voltadas para a participação dos estudantes, através do reconhecimento de suas falas, bem como pelos recursos que escolheram para compartilhar com os colegas. Durante os seminários, debates e na mostra interna, os alunos buscaram materiais, dinâmicas e exemplos que favorecessem a explicação de suas 
ideias. Apresentações em PowerPoint, debates intermediados por imagens disparadoras, vídeos - películas infantis, documentários, séries televisivas -, livros, propagandas, notícias, experimentos científicos, sites, dinâmicas reflexivas são exemplos dos diversos mecanismos selecionados pelos alunos. Para elaborar as análises, todas essas possibilidades são reconhecidas como recursos didáticos escolhidos e utilizados pelos estudantes a fim de favorecer a compreensão de seus colegas acerca dos conceitos pelos quais eram responsáveis em veicular. Privilegiamos nas análises as situações nas quais os estudantes se apropriaram das ideias expostas pelos autores em seus textos, elaborando associações, construindo, assim, concepções de ciência. Evidenciamos a intenção de dar voz aos professores em formação, valorizando sua participação ativa no processo.

É possível inferir que os alunos tenham feito essas escolhas pela dificuldade que muitos explicitaram ao compreender o próprio texto que apresentaram. Além de se depararem com uma variedade de assuntos, foram responsáveis por retratar conteúdos específicos que não dominavam. Ao serem questionados, ao final do curso, sobre motivos que os levaram a buscar novos recursos para explicarem os textos, uma aluna comentou: "Acho que quando constatamos que nós mesmos não entendemos, procuramos ferramentas. Aí quando entendemos, pensamos 'Ah, então eu posso explicar dessa forma pela qual eu entendi'”.

A composição de grupos heterogêneos, contemplando alunos com diferentes formações iniciais e interesses contribuiu para a compreensão dos textos, esclarecimento de conceitos, favoreceu debates de viés interdisciplinar e valorizou uma abordagem mais ampla de aspectos da ciência e da vida social como um todo, enriquecendo os debates. Foi evidente como estudantes das áreas de ciências cuidaram da explicação e exemplificação dos conteúdos científicos, enquanto pedagogos discorreram sobre o contexto histórico e trouxeram diversas relações com o campo da educação. Essa característica foi possível pela modalidade optativa, permitindo a circulação de alunos de cursos diferentes, pouco comum em disciplinas da pedagogia, mas mais frequente nas introdutórias dos cursos de licenciaturas ministrados na FEUSP.

\section{Construção de concepções de ciência e educação}

Como ponto de partida de nossa análise, utilizamos reflexões e discussões da Aula-síntese pelas sistematizações dos assuntos e conceitos trabalhados na disciplina. Caracterizamos as concepções de ciência e educação de acordo com os debates teóricos constituídos nas áreas de História da Ciência; de Ciência, Tecnologia e Sociedade (CTS); e da Ciência como Cultura.

Ao apresentar as percepções ao grupo, a pesquisadora optou por utilizar dinâmicas parecidas com as quais eles escolheram para a exposição de seus seminários - apresentação de PowerPoint, com elementos e exemplos externos ao conteúdo propriamente dito. Para organizar os dados sobre ciência, a pesquisadora elencou palavras-chave, levantadas a partir das falas dos estudantes, apresentando variados debates e, assim, compôs uma complexa concepção de ciência. 
Figura 1- Panorama de concepção de ciência — versão inicial

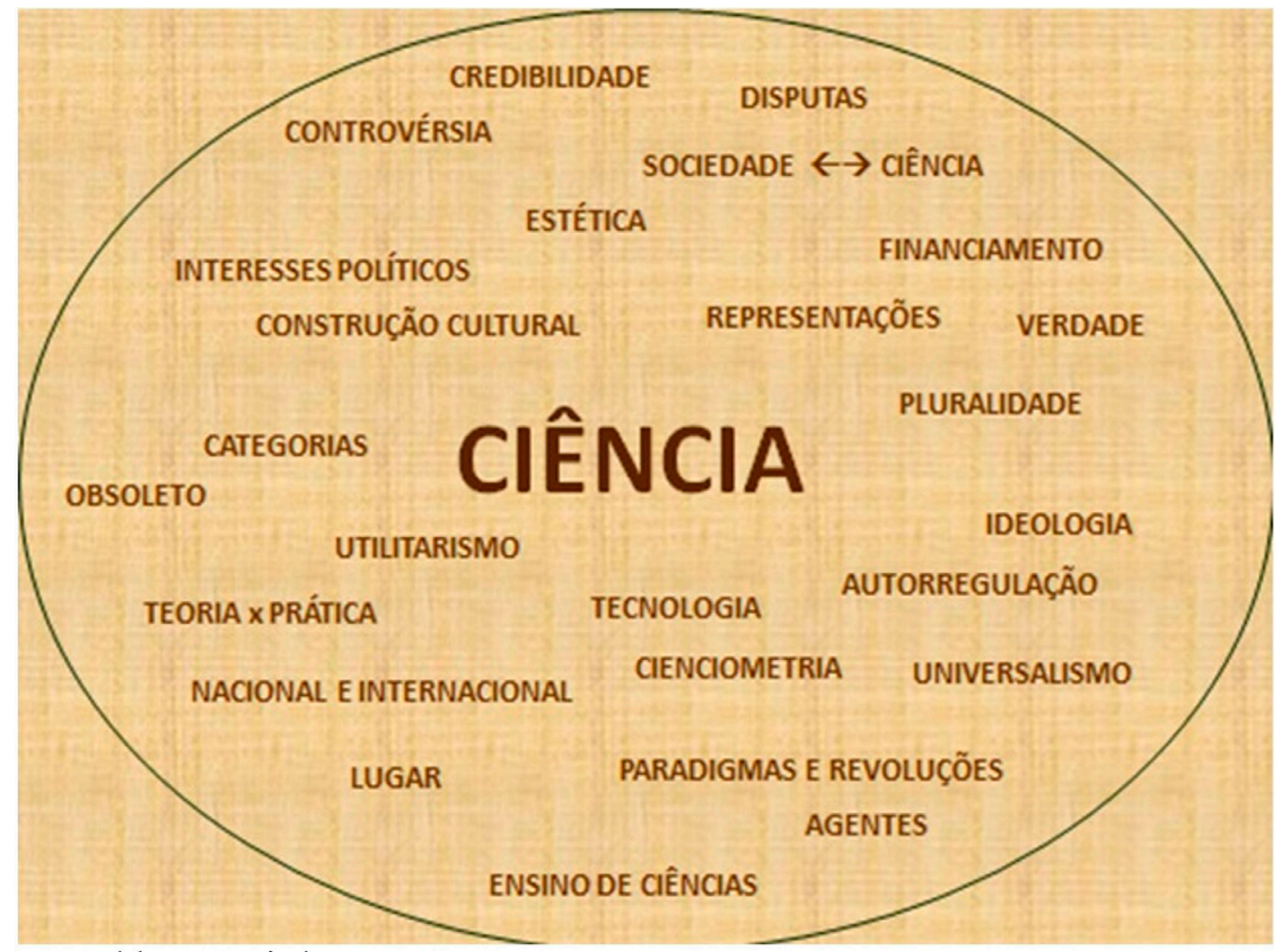

Fonte: Elaboração própria.

Apresentado esse quadro aos alunos, foram debatidos dois pontos principais. 0 primeiro foi se essa ideia de ciência como uma composição de diversos elementos, repleta de aspectos fazia sentido, se era possível compreender a intenção da pesquisadora ao organizar as percepções construídas na disciplina por meio dessa imagem-mosaico. Os estudantes concordaram e gostaram dessa maneira de olhar para a ciência como uma abordagem complexa.

A segunda questão foi se eles reconheciam suas compreensões nas palavras apresentadas. Nesse momento, alguns concordaram, mas outros sugeriram novas temáticas e conceitos a serem contempladas no quadro. Após as contribuições, o panorama foi modificado, apresentando a seguinte imagem final, sendo que em vermelho estão as novas ideias, sugeridas pelos alunos, sujeitos da pesquisa: 
Figura 2- Panorama de concepção de ciência - segunda versão, contemplando contribuições dos estudantes, em vermelho

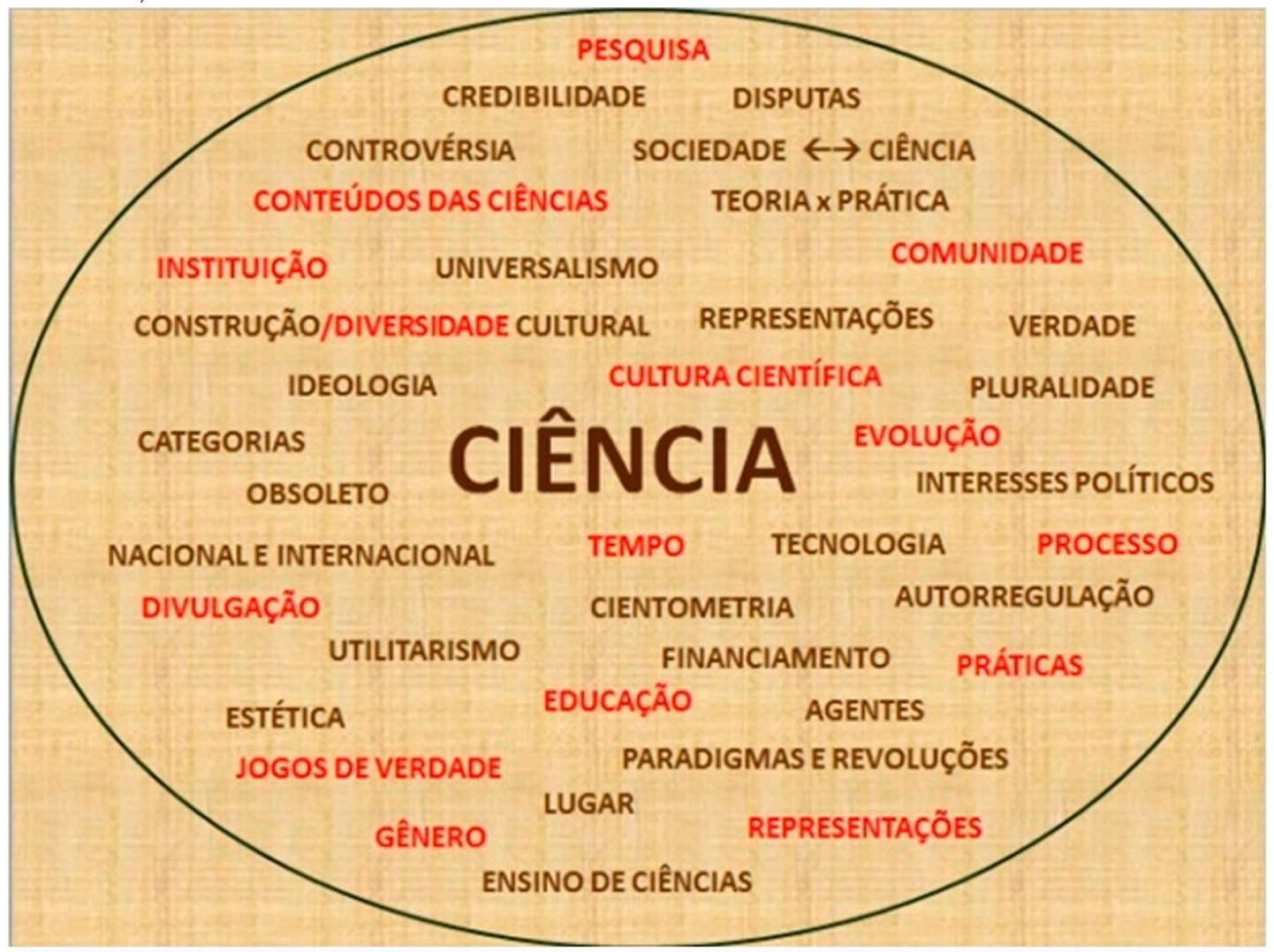

Fonte: Elaboração própria.

Além de apresentar o quadro de conteúdos, essa aula foi fundamental para articular debates, abordando considerações dos alunos sobre seus conceitos e suas práticas como docentes, suas expectativas anteriores à disciplina, pontos positivos do encontro com colegas de diversas áreas e proveitos dos estudos do meio, entre outros aspectos que validaram as reflexões e as experiências proporcionadas como positivas e formativas nos percursos acadêmicos e nos trabalhos como professores. Não sucederam opiniões discordantes, mas nem todos os alunos contribuíram com suas opiniões - não era uma proposta obrigatória. Por mais que não se possa afirmar que houve consenso no debate, é razoável inferir que os próprios alunos reconheceram contribuições das discussões em suas formações como educadores.

A seguir, analisaremos, em mais detalhes, como as principais concepções de ciência apresentadas nessa síntese (representadas em itálico ao longo do texto) foram construídas durante o curso, relacionando-as à bibliografia da área e aos referenciais da educação científica. Analisaremos as falas e recursos didáticos, desenvolvidos pelos estudantes, sem pretensão de evidenciar todas as possibilidades que ocorreram durante o curso, mas 
apenas para sintetizarmos as representações mais significativas das concepções de ciência e educação.

\section{Ciência e sua historicidade}

Durante a discussão na Aula-Síntese, a professora perguntou à turma sobre como eles relacionam esse quadro à sua formação. Uma aluna respondeu que "ficou uma visão mais democrática, menos mítica. Ajudou muito nessa questão de conscientização, de como a ciência é utilizada... De que existem interesses políticos...”. 0 reconhecimento do caráter histórico da ciência favorece a identificação dos processos científıcos. Pelas palavras de outra pedagoga em formação: "Na sala, o professor não vai ter tempo de explicar todos os processos. Mas pode deixar claro que isso existe. 0 fato de você saber que existe uma história muda sim a forma como você vai ensinar as crianças. Existe uma história por trás, muda o olhar".

Outra colega considerou:

A contextualização histórica de cada marco da ciência faz a gente refletir, [...] é um pano de fundo para pensar se um determinado conhecimento só surgiu agora ou se já havia surgido antes, mas só agora a sociedade permitiu que isso fosse discutido... Nos ajuda a refletir sobre a construção da ciência. (Coleta pessoal).

Nessas falas encontramos uma concepção de ciência em sua historicidade, ou seja, que a ciência deve ser compreendida em seu contexto histórico e em processos de construção do conhecimento assimilando as transformações científicas às dinâmicas sociais mobilizadas por interesses políticos e econômicos. A construção processual da ciência foi bem expressa nessas falas e mostra que, para compreendermos as teorias e práticas científicas, devemos tratar o período histórico em sua complexidade. 0 caráter reflexivo da $\mathrm{HC}$, destacado pelas alunas, foi vivenciado pelos professores em formação e poderá servir como um referencial metodológico em suas práticas de ensino. As percepções dos alunos foram resultado do estudo de um amplo panorama histórico do Renascimento ao século XX. Alguns alunos expressaram, na primeira aula, concepções de historicidade em ciências, como uma aluna de pedagogia, que já tinha feito iniciação científica na área de EC:

Acho importante estudar a história da ciência, porque muda não só o conteúdo, mas a forma como você trabalha. Até pessoalmente mesmo, às vezes a gente acha que as coisas vêm prontas, que a ciência vem pronta, porque as coisas foram apresentadas dessa forma na escola. Quando você estuda história da ciência, percebe que não é isso, que as coisas foram construídas historicamente. Então às vezes não faz sentido apresentar os símbolos prontos para as crianças. 0 que é óbvio para os professores não é óbvio para as crianças. É difícil, mas é importante tentar pensar em atividades que façam passar, não pelos mesmos processos do homem, mas por processos semelhantes. (Coleta pessoal). 
No processo de construção da historicidade foi possível traçar analogias entre a ciência desenvolvida atualmente e nos contextos históricos estudados nas aulas, apresentando abordagens diacrônicas da HC na construção conceitual. Nesse sentido, foram mobilizados muitos conceitos científicos, como o tempo, abordado em uma aula expositiva e retomado em outras que trataram do tempo geológico como conceito essencial para a construção do conceito de evolução, ambos estruturantes das ciências históricas da natureza. Destacamos aqui como essa abordagem conceitual, a partir da HC, favorece a construção de currículos no ensino superior, como salientado na literatura (COMPIANI; GONÇALVES, 1996). Na disciplina, verificamos como essa historicidade da ciência possibilitou a compreensão de conteúdos científicos pelos estudantes, de forma complexa e processual.

\section{Ciência, Tecnologia e Sociedade}

Referindo-se às contribuições da HC na formação dos pedagogos, através da construção da criticidade e da transitoriedade das ciências, uma estudante contemplou:

Eu acho que isso ajudou a gente a ter uma consciência mais forte, mais crítica com relação à ciência que a gente ensina. É que a gente passa conhecimentos como se fossem verdades absolutas, às vezes sem consciência de que eles são alteráveis, de que não foi sempre assim. É bom para a formação, pelo menos na pedagogia. (Coleta pessoal).

Essa fala da aluna sintetiza uma abordagem teórica da Ciência, Tecnologia e Sociedade (CTS) tratada ao longo da disciplina. As implicações entre ciência e sociedade ocorrem em dois sentidos. Por um lado, a ciência é capaz de influenciar a sociedade e gerar conhecimentos, tecnologias e produtos que circulem entre a população. Concomitantemente, a sociedade constitui a ciência e forma o cientista nela circunscrito. Por essa perspectiva, aproximações entre ciência e sociedade evidenciam que estão em constante (re)construção e em interferência mútua.

Segundo Figueirôa (1997), a ciência é parte da cultura como qualquer outra manifestação e não se diferencia nem carrega um status epistemológico superior em relação a outros conhecimentos culturais. Além disso, a ciência não ocorre em um vácuo social, pelo contrário, está contida em intrínsecas relações com elementos das esferas cultural, política, social, econômica e educativa do contexto no qual está inserida. Caracteriza a ciência como

[...] uma atividade exercida por seres humanos agindo e interagindo; portanto uma atividade social. Seu conhecimento, suas afirmações, suas técnicas foram criados por seres humanos e desenvolvidos, implementados e compartilhados por grupos de seres humanos. Conhecimento científico é fundamentalmente, portanto, conhecimento social. Como atividade social, a ciência é claramente um produto da história e dos processos que ocorreram no tempo e no espaço envolvendo seres humanos (FIGUEIRÔA, 1997, p. 20).

É consequência desse jogo de interesses no desenvolvimento das ciências a forte presença de controvérsias, disputas e negociações. Investigando sociologicamente 
o laboratório, Latour e Woolgan ([1979] 1997) reconhecem disputas entre equipes de cientistas em uma corrida por maior legitimidade. Por estarem nessa competição, os profissionais precisam desenvolver novos instrumentos e técnicas que os ajudariam a avançar ainda mais. Deflagram, então, que a importância das competições e negociações não é apenas um detalhe do trabalho do cientista, mas torna-se força motriz para o surgimento de novas proposições e tecnologias, desenvolvendo práticas e conhecimentos: objetos científicos.

Esse debate só faz sentido quando a base fundamental da discussão está na reflexão acerca da qualidade de verdade das asserções científicas. Pela historiografia, nota-se o processo em que a ideia de que o conhecimento científico deve traduzir uma verdade sobre a natureza vai aos poucos sendo modificada, chegando à noção de que se trata de uma leitura interessada, e não neutra, da realidade. Assim, adquire o caráter de credibilidade, legitimidade, e não mais os atributos de verdadeiro, dogmático e único. Isso se dá justamente pelo entrelaçamento dos aspectos: pelas imbricações entre as esferas social e científica, somado à questão das disputas e controvérsias, o conhecimento científico é produto de investigações vitoriosas, algo em que os homens creem com confiança, o que não significa que seja uma proposição verdadeira, mas uma leitura parcial da realidade legitimada por especialistas e seu entorno, de acordo com seus interesses.

Shapin (2013) esclarece que o conhecimento só adquire credibilidade em uma circunstância social, dependendo do consenso de uma comunidade, definitivamente marcada por determinados tempo, espaço e sujeitos envolvidos nessas atividades. É o produto de certas práticas sociais, contextualizadas em culturas específicas e dadas por seus respectivos sujeitos. Então, para avaliar a credibilidade de uma proposição, é fundamental verificar quando e onde foi desenvolvida. No entanto, por mais que na HFSC esse processo de transformação da qualidade de verdade em credibilidade venha sendo debatido, para a sociedade e muitos cientistas, a imagem da ciência permanece como detentora da verdade, autoridade, reveladora de mistérios.

$\mathrm{Na}$ disciplina, o grupo que tratou das ideias de Shapin acerca da construção social da verdade recorreu à análise de publicidades comerciais para explicar como a ciência depende da credibilidade para se sustentar na sociedade. Ao buscarem pela expressão "cientificamente comprovado" na plataforma Google, selecionaram exemplos de propagandas de emagrecimento, produtos para o cabelo crescer e medicamentos para a impotência sexual. Nesse primeiro exercício, os estudantes esboçam dois dos aspectos fundamentais para debater a concepção de ciência. Ao utilizar o cientificamente comprovado, reconhecem um termo recorrente e muito aceito como argumento verdadeiro, que autoriza a ciência a ditar como os corpos devem ser e, se não o são, como seria possivel remediar, sem abrir para discussões que contraponham os cientistas. Além disso, ao fazer a escolha dessas imagens do cotidiano, identificam a proximidade entre trabalho científico e sociedade, salientando a mútua influência entre os dois.

Dando continuidade a esse argumento e aprofundando um pouco mais, destacaram uma imagem da década de 1940 (Figura 3) em que médicos recomendam os cigarros Camel, legitimando o produto e, especificamente, essa marca. 
Figura 3- Publicidade de 1940

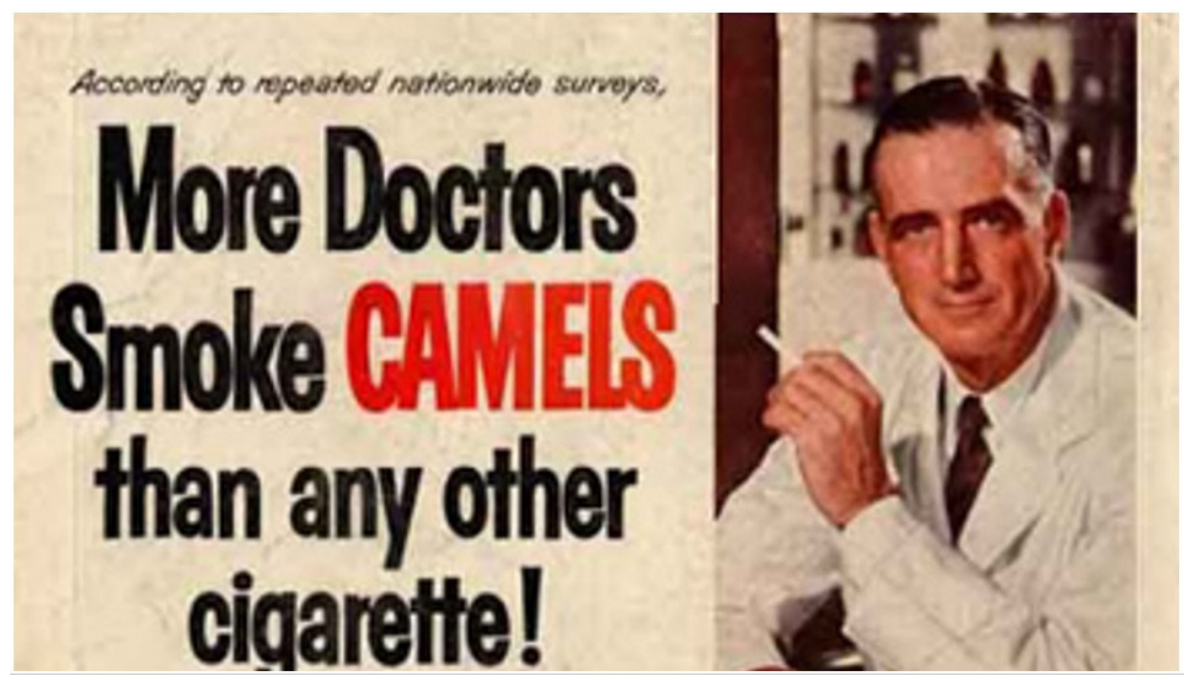

Fonte: http://www.wonderland.co.uk/.

Os estudantes explicitaram o interesse econômico das indústrias de cigarro na compra e utilização desse objeto e deflagraram a intenção de que essas atividades fossem validadas por um especialista. 0 efeito do uso desse slogan para ressaltar o caráter contingente da verdade está na historicidade dos valores sociais e científicos. Isto é, naquela época, os médicos, autoridades, validavam determinada prática social, mas atualmente essa atividade não é mais culturalmente valorizada nem é ligada à saúde.

Durante a apresentação das publicidades e debates acerca delas, houve risos na turma, o que reconhecemos como certa cumplicidade, tornando os recursos utilizados pelo grupo eficazes em sua comunicação e, principalmente, na apropriação do conceito de credibilidade. Além disso, essas manifestações podem ser analisadas como sensação de identidade, em que os estudantes percebem como eles mesmos estão inseridos nessa sociedade, causa e consequência da ciência, ao utilizar o termo cientificamente comprovado, ou ao validar esse tipo de slogans.

\section{Ciência como cultura}

Outro aspecto, fundamental para a elaboração de concepções de ciência, tecido durante a disciplina é o reconhecimento da ciência como cultura. As ciências já não são consideradas apenas como as hipóteses e teorias, mas ocorrem por um conjunto de diversas práticas científicas. Coletar, observar, mensurar, registrar, selecionar, classificar, nomear, desenvolver tecnologias, negociar, argumentar, discordar, divulgar, fazer experimentos, entre tantas outras ações, constituem o fazer científico. Elas podem acontecer em distintos espaços, como laboratório, campo, indústria, escola, mídia, entre outros. Uma vez que essas práticas ocorrem por sujeitos históricos, em espaços sociais, a ciência é também cultural. Conceber a ciência como cultura é: 
[...] erguer uma ponte, em termos culturais, da comunidade científica para o cidadão comum uma ponte ajustada ao exercício da cidadania que interligue cultura científica, cultura do fazer, cultura humanística e cultura de massa. Esta ponte requer uma reflexão sobre de que é que falamos quando falamos de cidadania, uma vez que toda e qualquer cidadania é um conceito em construção historicamente situado. (SANTOS, 2009, p. 532).

Durante a discussão sobre práticas de classificação na história natural, travada no seminário do texto de Lopes (2005), um aluno que assistia à apresentação atentou para a questão da tabela periódica: "Como existe um espaço para algo que não está descoberto? Isso também tem a ver com a lógica de classificação que tem por trás”. Em seguida, trouxe o exemplo da tecnologia do QRCode, como uma evolução do sistema de classificação, demonstrando que compreendeu que o que estava em debate não eram apenas sistemas de organização da botânica; mas que classificar e nomear são atividades humanas construídas social e culturalmente e aspectos constituintes das ciências. Por essa e outras situações parecidas, é possível caracterizar um olhar vertical para o aspecto da ciência: a classificação de qualquer coisa e que acontece toda hora é uma construção humana.

0 texto de Rossi (1989) associa história cultural e história das ciências ao problematizar a Revolução Científica, defendendo a tese de que a experimentação, ou o empirismo característico desta, foi resultado dos saberes práticos advindos dos artesãos, engenheiros e artistas desde o Renascimento em aproximação com o trabalho dos filósofos. Um dos principais argumentos do autor foi que a formação desses profissionais ocorria em espaços como os ateliês, onde se ensinavam pintura, escultura, anatomia, ótica, geometria, cálculo e perspectiva, afirmando-se como um espaço único, em que esses conhecimentos e experimentações compunham um só ofício. A partir dessas práticas, esses profissionais também mudam a construção de seu conhecimento, pois incorporam a matemática e outros saberes para a explicação de processos.

0 grupo responsável por esse seminário abordou a principal intenção do autor: superar a mentalidade que contrapunha radicalmente o trabalho científico apenas intelectualizado e teórico ao conhecimento produzido por práticas e experimentações realizadas manualmente - até então considerado inferior. Outro aspecto fundamental do debate foi o forte atrelamento entre as práticas científicas e as de ensino. Reconheceram a importância deste para reiterar, renovar e, sobretudo, construir o conhecimento científico. 0 ensino é o principal meio de divulgação, replicação e aprimoramento das proposições consolidadas.

As concepções do autor foram explicadas pelas alunas com o apoio de ampla variedade de imagens e vídeos, contemplando a construção dos instrumentos e a formação dos cientistas-artesãos. A contextualização do argumento do autor foi complementada pela problematização da historicidade dos recursos didáticos, ou seja, as representações dos diversos instrumentos foram fundamentais para explicar a aproximação entre a teoria e a prática.

Tal perspectiva marcou profundamente essas professoras em formação, pois, na mostra interna de recursos didáticos, optaram por apresentar um instrumento histórico. Construíram um periscópio adaptado, explicaram seu uso em determinado contexto histórico e o desuso, a partir da criação dos radares sonoros. Ainda que esse tipo de instrumento não 
seja mais utilizado em submarinos, as pedagogas admitem sua importância para o ensino. A partir de uma abordagem histórica e tendo em mente essa concepção complexa de ciência, a atividade pode ir além dos conteúdos científicos - propriedades físicas - e proporcionar debates de maneira mais reflexiva e crítica com relação à construção do conhecimento.

$\mathrm{Na}$ literatura encontramos alguns exemplos de criação de metodologias do ensino centradas na construção histórica das práticas científicas, como trabalhos de campo (BANDEIRA, 2015), instrumentos (VISSICARO, 2014) ou experimentos. Tais abordagens problematizam a epistemologia das práticas, ultrapassando um EC calcado exclusivamente na construção conceitual ou na realização de práticas de forma prescritiva, dissociadas da teoria.

\section{História da ciência e história da educação}

Além de explorarmos a construção de estratégias envolvendo a HC no ensino, durante a disciplina foram abordados contextos históricos nos quais era possível perceber que as transformações na ciência também modificavam as teorias e práticas educacionais, como expresso por uma pedagoga na Aula-síntese:

Às vezes a gente sai da nossa área e vai pra uma outra. E, quando a gente está em outras, a gente vê coisas escancaradas que estão na educação só que a gente não percebe quando está nessa área. Então por exemplo, no texto do Kuhn, a gente viu a questão de mundo mesmo. Ficou muito claro pra gente que nas ciências tem diferentes visões de mundo. Só que a gente acha que na educação não tem. E quando você vai ver, você tem que ler um texto de ciências pra perceber que na educação tem diferentes visões de mundo, sim. (Coleta pessoal).

A aluna expressou como as visões de mundo, presentes na ciência, estruturam a educação. Na teoria de Kuhn ([1962] 2013) o ensino, bem como manuais universitários e materiais para esse fim, são fundamentais para o estabelecimento de um novo paradigma, após o período conturbado da revolução. É pelo processo de transmissão de conhecimento que a ciência pode se consolidar ainda mais, formando o olhar dos jovens cientistas de acordo com a nova ciência normal.

Relações entre a história da ciência e a história da educação também foram explicitadas pelo grupo que explorou as ideias de Abrantes (1998) ao analisar o contexto da Revolução Francesa. Enfatizaram a aproximação entre ciência e sociedade, revelando a ideia de que se há diferenças nas ideologias políticas, há divergências também nas concepções de ciência que as acompanham: o Estado promove atividades científicas e a comunidade científica envolve-se nos negócios do Estado. Neste contexto de disputas, há também alterações na educação. No Antigo Regime, a educação formal estava nas mãos do clero e o ensino superior era para poucos, havia valorização das belas artes e raro reconhecimento das ciências naturais. Após a queda da monarquia, o ensino privilegiou as práticas, artes e ofícios, voltando-se para o militarismo e a tecnologia em geral. As mudanças nas concepções exercidas no ensino, alterando conteúdos, métodos de ensino e público favorecido que frequentaria as instituições escolares, estão aliadas às novas concepções de ciência e de sociedade. Pelas palavras de um integrante do grupo, que é formado em história e estava cursando pedagogia: 
A ideia central desse texto é entender que as ideias estão em disputa. Uma ideia de ciência e de finalidade da ciência, o porquê do fazer científico... Essas ideias estão em disputa. Isso faz com que o projeto de educação científica passe também a estar em disputa. Quem vai ter acesso a esse conhecimento... Como esse acesso vai ser dado... Quem tem direito a ter esse acesso... Que formação será oferecida... [...] As discussões políticas vão questionar a forma de ver e de fazer ciência... Qual será a forma de divulgação científica? Nada está pronto. (Coleta pessoal).

Com esta fala, fica clara a percepção dos estudantes de que o currículo e o acesso à escola e ao conhecimento científico são determinados por interesses políticos. Ou seja, o EC ocorre de acordo com a concepção de ciência em voga e está a favor dela, que, por sua vez, está atrelada às ideologias e intenções políticas que estão em disputa a cada período histórico da humanidade.

\section{Considerações finais}

Como já abordado, está explícita na literatura a intenção de incorporar a perspectiva da HSFC no ensino básico e, em especial, nos processos de formação de professores de ciências com o objetivo de favorecer a perspectiva emancipatória, política e reflexiva do sujeito na construção de uma concepção humanista de ciência e educação. Assim, sua própria percepção crítica é desenvolvida e, depois, poderá trabalhar os conteúdos curriculares por essa abordagem no ensino-aprendizagem. Na experiência analisada neste artigo verificamos essas contribuições para a formação de professores, além de abordarmos outros aspectos, tanto na escolha de textos quanto nos recursos desenvolvidos pelos alunos. Aqui se destaca também a importância de considerar o pedagogo, não só por ensinar ciências, mas também por trabalhar com o conhecimento e sua interface com a sociedade na atividade docente.

Durante os seminários, os alunos buscaram o próprio entendimento dos conceitos e práticas científicas por meio de leituras complementares sobre as biografias dos cientistas, o aparato experimental, as práticas de observação, as representações, enfim, a complexidade do fazer científico e suas relações com os contextos histórico-sociais. Esses materiais e informações foram utilizados como recursos didáticos, frequentemente associados a demonstrações e reflexões sobre possiveis abordagens no ensino, revelando o quanto os professores em formação podem exercitar a prática docente através de sua própria construção do conhecimento. Essa perspectiva em sua formação lhes propicia recursos e metodologias para trabalhar os conteúdos científicos e suas imbricações históricas, sociais, práticas e educativas em sua atividade profissional, atingindo a sala de aula e os alunos.

As discussões historiográficas favorecem, então, a superação de uma abordagem puramente conteudista no EC, para uma formação de educadores que problematizam tanto a construção teórica, quanto o desenvolvimento prático, através da historicidade na compreensão da ciência em seu contexto. Em tal processo, é contemplada a compreensão da ciência associada às esferas social, econômica, política, educativa, repleta de controvérsias, disputas, negociações, cujas proposições são organizadas pela noção da credibilidade. Isso contribui para a educação para a cidadania. A concepção de ciência como cultura ilumina 
aspectos científicos que vão além das teorias. 0 fazer científico, contemplando seus instrumentos, práticas e representações é fundamental para a compreensão de ciência, além de que sempre esteve e está atrelado ao ensino científico.

A constante busca dos estudantes por construir relações entre os conceitos científicos ou históricos com a educação foi recorrente pela escolha dos textos abordados na disciplina. Além disso, apontar esse tipo de questões faz parte de sua identidade docente e é constantemente estimulada na faculdade de educação. Durante a leitura e interpretação dos textos clássicos sobre HFSC, elaboraram analogias com o ensino e com autores estudados em disciplinas de fundamentos da educação (história, filosofia e sociologia da educação). Ao reconhecer que as controvérsias e disputas pelas quais a ciência se desenvolve são semelhantes às escolhas pedagógicas que o educador deve fazer e também que elas se dão por diferenças de interesses e influências sociais e econômicas nas escolhas escolares, professores em formação se identificaram com tais debates na esfera científica, e então puderam se expressar sobre questões de educação às quais eles mesmos são críticos.

\section{Referências}

ABRANTES, Paulo. Imagens de natureza, imagens de ciência. Campinas: Papirus, 1998.

ALVIM, Márcia; ZANOTELLO, Marcelo. História das ciências e educação científica em uma perspectiva discursiva: contribuições para a formação cidadã e reflexiva. Revista Brasileira de História da Ciência, Rio de Janeiro, v. 7, n. 2, p. 349-359, 2014.

BANDEIRA, Camila Martins da Silva. Expedição pelo Riacho do Ipiranga: história, ciência e ambiente na educação. 2015. Dissertação (Mestrado) - Faculdade de Educação da Universidade de São Paulo (USP). São Paulo, 2015.

BRASIL. Ministério da Educação. Parâmetros Curriculares Nacionais - terceiro e quarto ciclos do ensino fundamental - ciências naturais. Braília, DF: ME, 1998. Disponível em: <http://portal.inep.gov.br/web/ saeb/parametros-curriculares-nacionais>. Acesso em: jul. 2016.

CHINELLI, Maura Ventura; FERREIRA, Marcus Vinicius da Silva; AGUIAR, Luiz Edmundo Vargas de. Epistemologia em sala de aula: a natureza da ciência e da atividade científica na prática profissional de professores de ciências. Ciência \& Educação, Bauru, v. 16, n. 1, p. 17-35, 2010.

COMPIANI, Maurício; GONÇALVES, Pedro Wagner. Epistemologia e historia de la geología como fuentes para la selección y organización del curriculum. Enseñanza de las Ciencias de la Tierra, Girona, v. 4, n. 1, p. 38-45, 1996.

DOMINGUES, Heloisa Maria Bertol; SÁ, Magali Magali Romero. Controvérsias evolucionistas no Brasil do século XIX. In: DOMINGUES, Heloisa Maria Bertol; SÁ, Magali Romero; CLICK, Thomas (Org.). A recepção do darwinismo no Brasil. Rio de Janeiro: Fiocruz, 2003. p. 97-123.

DUARTE, Maria Conceição. A história da Ciência na prática de professores portugueses: implicações para a formação de professores de Ciências. Ciência \& Educação, Bauru, v. 10, n. 3, p. 317-331, 2004. 
EZPELETA, Justa; ROCKWELL, Elsie. Pesquisa participante. São Paulo: Cortez, 1986.

FIGUEIRÔA, Silvia Fernanda de Mendonça. História e filosofia das geociências: relevância para o ensino e formação profissional. Terrae Didatica, Campinas, v. 5, n. 1, p. 63-71. 2009.

FIGUEIRÔA, Silvia Fernanda de Mendonça. Marcos para uma história das ciências no Brasil. In: FIGUEIRÔA, Silvia Fernanda de Mendonça. As ciências geológicas no Brasil: uma história social e institucional - 18751934. São Paulo: Hucitec, 1997. p. 15-32.

FORATO, Thais Cyrino de Mello. A natureza da ciência como saber escolar: um estudo de caso a partir da história da luz. 2009. Tese (Doutorado) - Faculdade de Educação da Universidade de São Paulo, São Paulo, 2009.

GANDOLFI, Haira Emanuela. A natureza da química em fontes históricas do Brasil colonial (1748-1855): contribuições da história da exploração mineral para o ensino de química. 2015. Dissertação (Mestrado) Universidade Estadual de Campinas, Campinas, 2015.

GANDOLFI, Haira Emanuela; FIGUEIRÔA, Silvia Fernanda de Mendonça. Formação de professores e pesquisa em história das ciências. EDUCA, v. 4, n. 8, p.3-28, maio/ago. 2017.

GHEDIN, Evandro; FRANCO, Maria Amélia Santoro. Questões de método na construção da pesquisa científica. São Paulo: Cortez, 2008.

HODSON, Derek. In search of meaningful relationship: an exploration of some issues relating to integration in Science and Science education. International Journal of Science Education, v. 14, n. 5, p. 541-562, 1992.

KUHN, Thomas. Estrutura das revoluções científicas. São Paulo: Perspectiva, 12 ed. [1962], 2013.

LATOUR, Bruno; WOOLGAR, Steve. A vida de laboratório: a produção dos fatos científicos. Rio de Janeiro: Relume Dumará, [1979], 1997.

LIMA, Nísia Trindade; HOCHMAN, Gilberto. Condenado pela raça, absolvido pela medicina: o Brasil descoberto pelo movimento sanitarista da Primeira República. In: MAI0, Marcos Chor; SANTOS, Ricardo Ventura (Org.). Raça, ciência e sociedade. Rio de Janeiro: Fiocruz, 1996. p. 23-40.

LOPES, Maria Margaret. Culturas das ciências naturais. Ciência \& Educação, Bauru, v. 11, n. 3, p. 457-470, 2005.

MATTHEWS, Michael. História, filosofia e ensino de ciências: a tendência atual de reaproximação. Cadernos Catarinenses de Ensino de Física, Florianópolis, v. 12, n. 3, p. 164-214, 1995.

MAYR, Ernest. Biologia, ciência única. São Paulo: Companhia das Letras, 2005.

MERTON, Robert. Ensaios de sociologia da ciência. São Paulo: 34, [1936], 2013.

NEWERLA, Vívian Branco. Rios vistos e revistos: as expedições de exploração do sertão da comissão geográfica e geológica na história da ciência e ensino de ciências naturais. 2000. Dissertação (Mestrado) - Instituto de Geociências da Universidade de Campinas, Campinas, 2000.

PATACA, Ermelinda Moutinho. Coleta, transporte e aclimatação de plantas no Império luso-brasileiro (17771822). Museologia \& Interdisciplinaridade, Brasília, DF, v. 5, n. 9, p. 88-108, 2016. 
PRICE, Derek de Solla. 0 Relógio Celeste na Grécia e na China. In: PRICE, Derek de Solla. A ciência desde a Babilônia. São Paulo: Edusp, 1976. p. 37-55.

ROSSI, Paolo. Os filósofos e as máquinas. São Paulo: Companhia das Letras, 1989.

SANTOS, Maria Eduarda. Cidadania, conhecimento, ciência e educação CTS: rumo a novas dimensões epistemológicas. Revista Iberoamericana de Ciencia Tecnología y Sociedad, Buenos Aires, v. 2, n. 6, p. 137-157, 2005.

SANTOS, Maria Eduarda. Ciência como cultura: paradigmas e implicações epistemológicas na educação científica escolar. Química Nova, São Paulo, v. 32: n. 2, p. 530-537, 2009.

SCMIEDECKE, Winston Gomes. A história da ciência nacional na formação e na prática de professores de física. 2016. Tese (Doutorado) - Interunidades em Ensino de Ciências, Universidade de São Paulo, São Paulo, 2016.

SHAPIN, Steven. Nunca pura: estudos históricos de ciência como se fora produzida por pessoas com corpos, situadas no tempo, no espaço, na cultura e na sociedade e que se empenham por credibilidade e autoridade. Belo Horizonte: Fino Traço, 2013.

SILVA, Michele Alves da. História da ciência - contribuição à cidadania no ensino fundamental I: propostas didáticas. 2014. Dissertação (Mestrado) - Universidade Federal do ABC, Santo André, 2014.

THE WONDERLAND TIMES. Disponível em: <http://www.thewonderland.co.uk/blog/publicity-can-comefrom-the-most-unexpected-corners>. Acesso em: abr. 2018.

VISSICARO, Suseli de Paula. A construção de uma proposta didático-pedagógica a partir da história dos instrumentos de navegação marítima dos portugueses. 2014. Dissertação (Mestrado em Ensino, História e Filosofia das Ciências e Matemática) - Universidade Federal do ABC, Santo André, 2014.

Recebido em: 18.10.2017 Revisões em: 03.04.2018 Aprovado em: 16.05.2018

Gabriela Marko possui graduação em pedagogia pela Faculdade de Educação da Universidade de São Paulo (2011), com Iniciação Científica em Sociologia da Educação. É mestre (2018) em educação pela mesma faculdade.

Ermelinda Moutinho Pataca é professora da Faculdade de Educação da Universidade de São Paulo (USP). Possui graduação em licenciatura em química pela Universidade Estadual de Campinas (1996), mestrado (2001) e doutorado (2006) em educação aplicada às geociências pela Universidade Estadual de Campinas e livre-docência pela Faculdade de Educação da USP. 